\title{
A Low Power MEMS Silicone/Parylene Valve
}

\author{
Xing Yang, Charles Grosjean, and Yu-Chong Tai \\ Caltech Micromachining Laboratory \\ Electrical Engineering, 136-93 \\ California Institute of Technology \\ Pasadena, CA 91125
}

\begin{abstract}
A low power thermopneumatic MEMS valve utilizing several novel components has been developed. $61 \mathrm{~mW}$ of power is sufficient to control a nitrogen flow of $1.1 \mathrm{lpm}$ with an inlet pressure of 24 psi. Previous work [1,3] has shown that silicone rubber has a low Young's modulus $(\sim 1 \mathrm{MPa})$ and exhibits good sealing properties. Thermopneumatic actuation $[\mathbf{1 , 2}]$ has the potential for large forces through long displacements. By using a "soft" membrane with a large gap, and thermopneumatic actuation, high flow rates are achievable while still keeping power consumption low. However, silicone has been shown to be permeable to a wide range of liquids including Fluorinert ${ }^{\mathrm{TM}}$ which necessitates the addition of a barrier layer, in this case Parylene $C$. This paper presents a low power valve constructed with a composite silicone/Parylene membrane, a suspended heater for low heat loss through conduction, and a valve seat designed for improved sealing and particle resistance.
\end{abstract}

\section{INTRODUCTION}

Several MEMS silicone rubber membrane valves $[\mathbf{1 , 3 , 5 ]}$ have been developed in the past. Silicone rubber has a low Young's modulus $(\sim 1 \mathrm{MPa})$, good compatibility with IC processes, high elongation $(100 \%-1,000 \%)$ and good sealing properties on rough surfaces. Previously, we reported [1] a MEMS silicone membrane valve. The valve consisted of a cavity filled with a working fluid and sealed with a glass substrate heater on one side and a silicone membrane on the other. Using thermopneumatic actuation, large deflections were obtained compared to devices using silicon membranes [2]. Although good performance was achieved, the working fluid would leak through the permeable silicone membrane in a matter of days rendering the valves unusable. The solution was a composite membrane with a vapor barrier for keeping the working fluid in the cavity and a layer of silicone for sealing purposes. Most IC compatible materials that are impermeable to our chosen working liquids have very high modulus which defeats the purpose of a silicone membrane valve, but Parylene $C$ is an effective barrier and has a fairly low modulus. The power consumption of the valve was high, and in part due to the design of the heater as a gold resistor on a glass substrate. A large portion of the input power would go into heating the substrate rather than the working fluid and computer simulation shows that $98 \%$ of the heat generated by a heater can be lost through the glass substrate [4]. To remedy this, we have designed a heater with the resistive element suspended on a thin silicon nitride membrane. Because of the small cross section of the membrane and the inherent low thermal conductivity of $\mathrm{Si}_{x} \mathrm{~N}_{y}$, the heat lost to the substrate and environment is minimized. Finally, we have developed a corrugated valve seat optimized for the compliant silicone membrane. The outlet hole is surrounded by concentric grooves to create redundant seals and reduce the chance of a leak due to particles.

\section{DESIGN AND FABRICATION}

Load deflection tests [6] were used to determine the Young's modulus of MRTV1 silicone rubber $(0.51 \mathrm{MPa})$ and Parylene $\mathrm{C}$ (4.5 GPa) which are both orders of magnitude lower than silicon. To keep the membranes fairly soft, a very thin layer of Parylene was used compared to the silicone thickness when fabricating the composite membranes. As it was suspected that silicone absorbs Fluorinert $^{\mathrm{TM}}$, the Parylene layer was kept next to the liquid. The process flow for the composite membrane is shown in Fig. 1. A $<100>$ wafer is oxidized and patterned on both sides prior to $\mathrm{KOH}$ etching to form two cavities. The top cavity is $5 \mathrm{~mm} \times 5 \mathrm{~mm}$ and

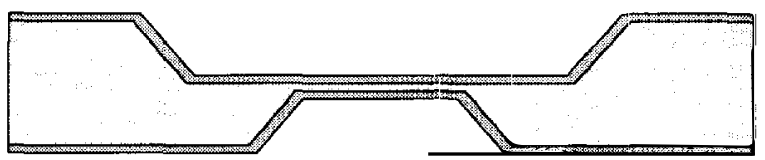

Etch cavities from both sides and deposit $\mathrm{Si}_{\mathrm{x}} \mathrm{N}_{\mathrm{y}}$

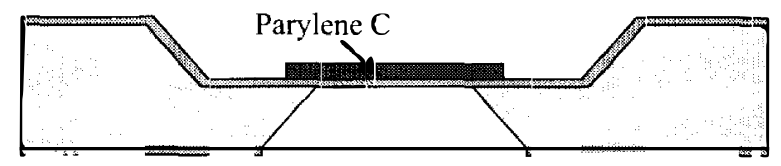

Etch away Si from backside to from a $\mathrm{Si}_{\mathrm{x}} \mathrm{N}_{\mathrm{y}}$ membrane and deposit Parylene on front side

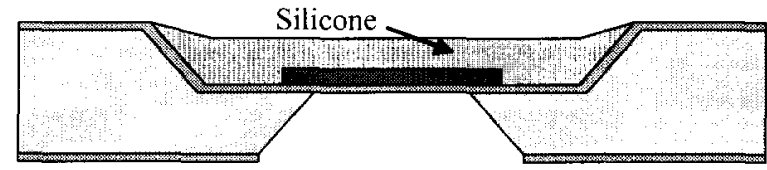

Mold silicone rubber on front side



Etch away $\mathrm{Si}_{x} \mathrm{~N}_{y}$ from backside and deposit second layer of Parylene $\mathrm{C}$

Figure 1. Composite membrane fabrication process 
Silicon Nitride

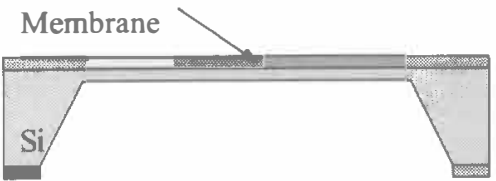

$\mathrm{KOH}$ Etching



$\mathrm{Cr} / \mathrm{Au}$ Deposition and Patteming

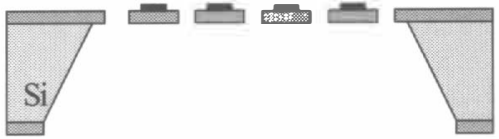

Silicon Nitride Patterning

Figure 2. $\mathrm{Si}_{x} N_{v}$ membrane heater fabrication process

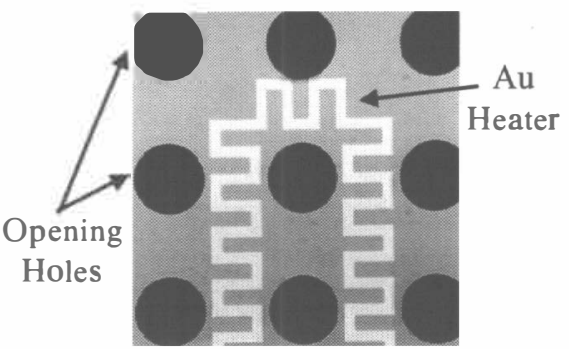

Figure 3. Fabricated $\mathrm{Si}_{x} \mathrm{~N}_{y}$ membrane heater showing the holes that equalize the pressure across the membrane during valve operation.

serves as a mold for the silicone rubber. The bottom cavity serves as the reservoir for the working fluid and defines the dimensions of the final composite membrane which is $2.7 \mathrm{~mm} \times 2.7 \mathrm{~mm}$. The $520 \mu \mathrm{m}$ thick wafer is etched $235 \mu \mathrm{m}$ on each side in $\mathrm{KOH}$ leaving a $50 \mu \mathrm{m}$ thick silicon membrane. A $0.5 \mu \mathrm{m}$ low-stress $\mathrm{Si}_{\mathrm{x}} \mathrm{N}_{\mathrm{y}}$ film is deposited on both sides and the $\mathrm{Si}_{x} \mathrm{~N}_{y}$ on the backside is removed using $\mathrm{SF}_{6} / \mathrm{O}_{2}$ plasma. The wafer is put back into $\mathrm{KOH}$ to etch away the silicon layer and a $\mathrm{Si}_{\mathrm{x}} \mathrm{N}_{\mathrm{y}}$ membrane is formed. Then, $2 \mu \mathrm{m}$ of Parylene $C$ is deposited and patterned at the bottom of the top cavity, followed by the molding of MRTVI silicone rubber into the top cavity. The backside nitride is patterned using $\mathrm{SF}_{6} / \mathrm{O}_{2}$ plasma to free the membrane. Finally, another layer of $2 \mu \mathrm{m}$ thick Parylene $\mathrm{C}$ is deposited on the backside to strengthen the edge of the membrane.

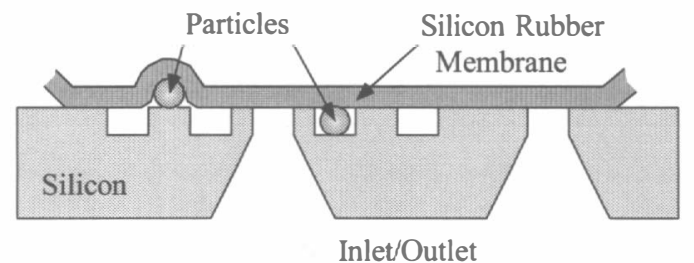

Figure 4. New Valve Seat Design, the corrugated valve seat creates redundant seals and reduce the chance of a leak due to particles.



(a) $\mathrm{Si}_{x} \mathrm{~N}_{y}$ membrane heater

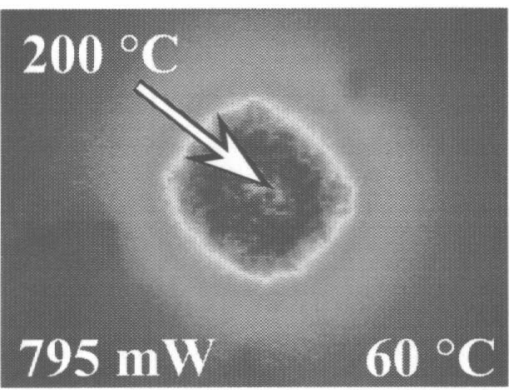

(b) Glass Susbstrate Heater

Figure 5. 2-D temperature profile of heater surface; to reach the same temperature on the surface, the $\mathrm{Si}_{x} \mathrm{~N}_{y}$ membrane heater requires much less power than the glass substrate heater.

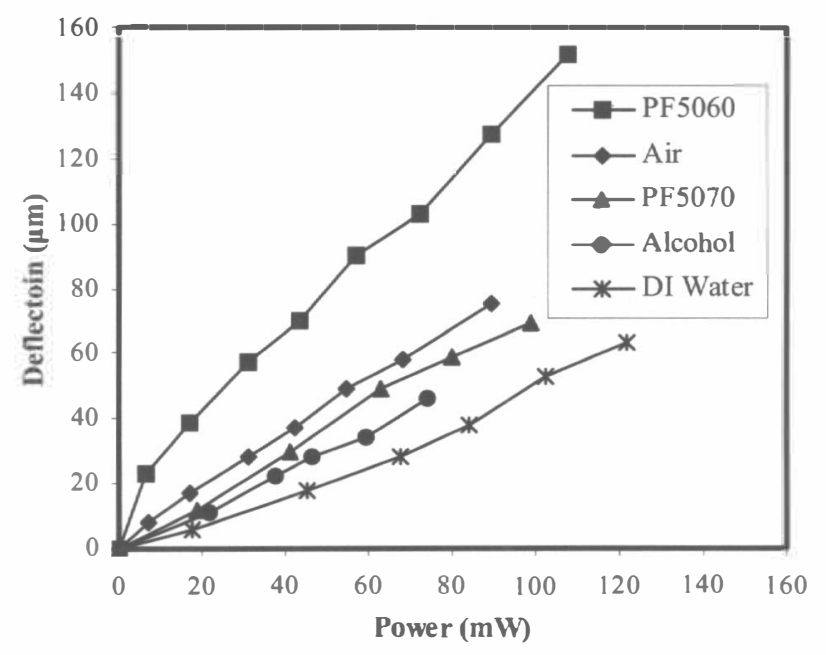

Figure 6. Thermopneumatic actuation, Fluorinert ${ }^{T M} P F-5060$ gives the best thermopneumatic actuation performance.

For improved thermal isolation, the gold heater is patterned on a suspended $\mathrm{Si}_{x} \mathrm{~N}_{y}$ membrane formed by $\mathrm{KOH}$ etching. As shown in Fig. 2, $\mathrm{KOH}$ etching is used to form a silicon frame with a free standing $\mathrm{Si}_{x} \mathrm{~N}_{y}$ membrane. Then a layer of $100 \AA$ $\mathrm{Cr} / 5000 \AA \mathrm{Au}$ is evaporated and patterned to define the heater. Finally, an array of $200 \mu \mathrm{m}$ diameter holes is etched in the $\mathrm{Si}_{x} \mathrm{~N}_{y}$ membrane using $\mathrm{SF}_{6} / \mathrm{O}_{2}$ plasma. These holes equalize the pressure across the heater membrane during valve operation. Fig. 3 shows a fabricated heater.

The new valve seat is designed to form redundant sealing rings so that poor seals due to particles don't compromise the 
performance of the valve. Instead of two simple holes for the inlet/outlet, $30 \mu \mathrm{m}$ wide grooves are etched into the silicon substrate by RIE. As shown in Fig. 4, these grooves reduce the chance of the particles sticking near the inlet/outlet.

\section{THERMOPNEUMATIC ACTUATION}

The thermal performance of the $\mathrm{Si}_{\mathrm{x}} \mathrm{N}_{\mathrm{y}}$ membrane heater and glass substrate heater is studied using an infrared thermal imager. The results are shown in Fig. 5. The $\mathrm{Si}_{x} \mathrm{~N}_{y}$ membrane heater surface reaches $200{ }^{\circ} \mathrm{C}$ with only $52.2 \mathrm{~mW}$ power input while the glass heater requires $795 \mathrm{~mW}$ power input for the same temperature. This confirms that the $\mathrm{Si}_{x} \mathrm{~N}_{y}$ membrane provides better thermal insulation.

To test the thermopneumatic actuation efficiency of various working liquids, a variety of actuators were assembled (valves without valve seats). Actuation was observed by applying a fixed amount of power to the cavity and measuring deflection of the membrane from its rest position under a microscope. Fig. 6 shows the results for DI water, Fluorinert ${ }^{\mathrm{TM}}$ (PF-5060, PF-5070), isopropanol, and air. With the same power input to the heater, the actuator sealed with PF-5060 achieved the highest deflection among all the liquids. Because of the high temperatures achievable with the $\mathrm{Si}_{x} \mathrm{~N}_{y}$ membrane heaters, it is necessary to use a fully filled liquid cavity to prevent bubble formation on the heater. Tests with an air-filled cavity resulted in heater damage at high power and plastic deformation in the silicone/Parylene membrane.

By using the method of laser interferometry, the transient response of the thermopneumatic actuator was studied. By applying a square wave to the heater of the actuator, the deflection of the actuator as a function of time was measured using a laser interferometer. In most cases, the response has two time constants, a short one which is associated with heating the working liquid in the cavity and a long one which is associated with heating the whole chip package. A heater with good thermal insulation consumes less power, but it also takes longer for the heat to dissipate. There is a trade-off between the power consumption and operation speed. Experimentally, it was found that for actuators with a fixed volume, thermal properties (specific heat, density, and thermal conductivity) of the working fluids change the transient response of thermopneumatic actuators. The actuators with air as the working fluid has the shortest time constant among all the fluids. The reason is although air has a very low thermal conductivity, its density is dramatically lower than all the liquids.

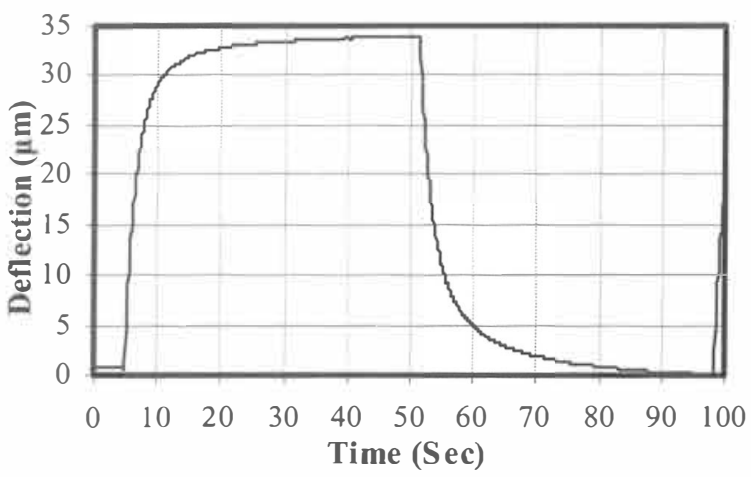

Figure 7. Transient response of thermopneumatic actuation as measured with a laser interferometer for an actuator filled with PF56060 with a glass backing plate on a metal heat sink

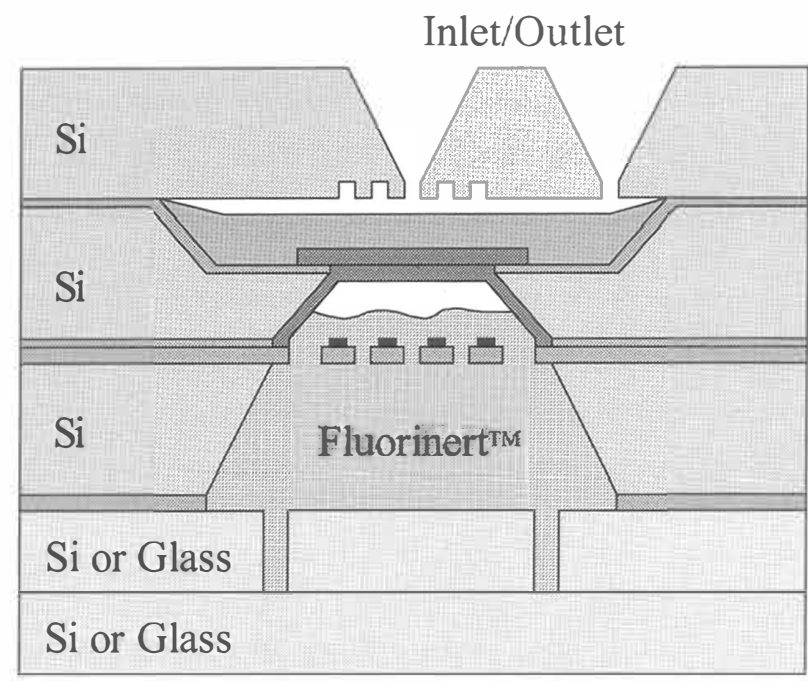

Figure 8.Cross-Section of the Valve

The package design of the actuators will also change the response. By using a silicon backing plate for the actuator or attaching a metal heat sink underneath the actuator, the response of the actuator will be faster while the power consumption will be higher. For example, an actuator with PF-5060 as the working fluid has heating time constants of $1.7 \mathrm{sec}$ and $38.2 \mathrm{sec}$, cooling time constants of $2.1 \mathrm{sec}$ and $37.0 \mathrm{sec}$. As shown in Fig. 7, when a metal heat sink is attached, the heating time constants become 1.5 sec and $7.1 \mathrm{sec}$ and cooling time constants become $1.8 \mathrm{sec}$ and 9.4 $\mathrm{sec}$, which agrees with theoretical calculations.

\section{VALVE PERFORMANCE}

Valves are made by assembling a valve seat die, membrane chip die, heater die and backing plate. Fig. 8 shows the crosssectional view of the valve. Fig. 9 is the picture of a fully packaged valve. It should be noticed that the 50 to $60 \mu \mathrm{m}$ recess of the cured silicone rubber film defines the gap between the membrane and valve seat, which simplifies the fabrication of the valve seat. The inlet and outlet of the valve seat are 500 by 500 $\mu^{2}$. As suggested by the thermopneumatic actuation results, all the valves are fully filled with Fluorinert ${ }^{\mathrm{TM}} \mathrm{PF}-5060$. The valves were tested and the results are shown in Fig. 10. Under inlet



Figure 9. Picture of a fully packaged valve 


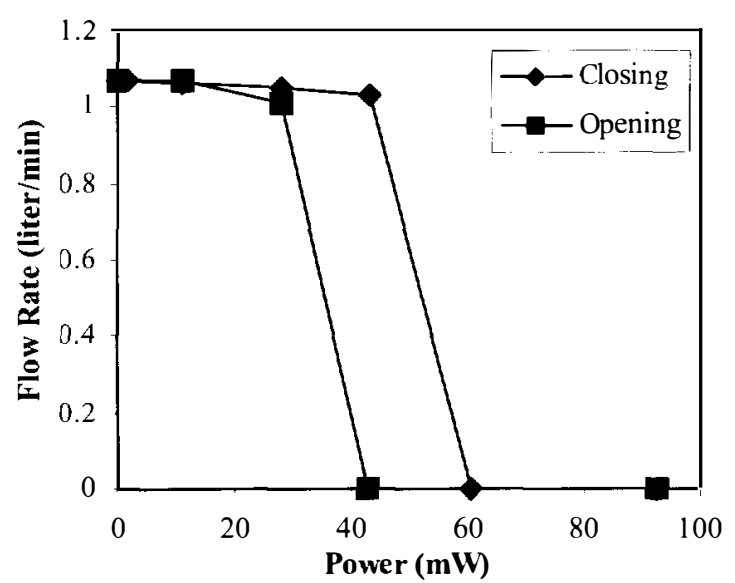

(a) Inlet Pressure $=24$ psi

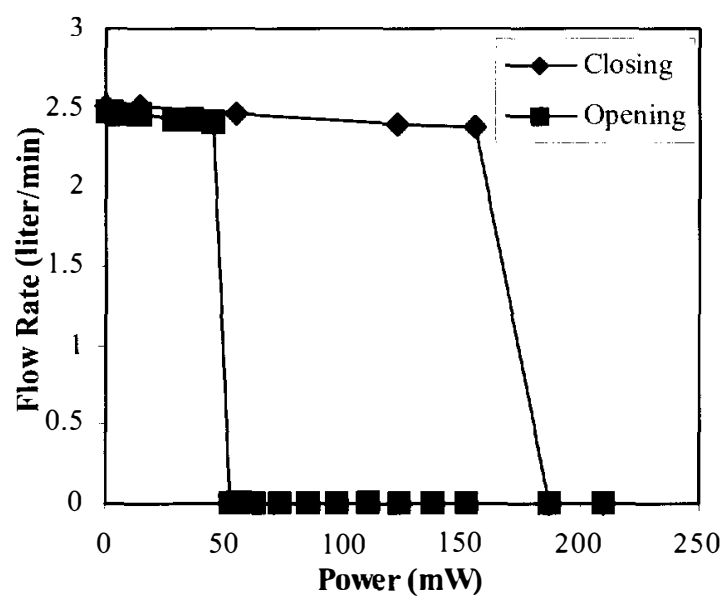

Inlet Pressure $=54$ psi

Figure 10. Valve performance using nitrogen showing low power operation and hysterisis due to good thermal insulation.

pressure of $24 \mathrm{psi}$, a power input of $61 \mathrm{~mW}$ is enough to shut off a nitrogen flow of $1.1 \mathrm{liter} / \mathrm{min}$. The valve has been tested up to 70 psi without any damage. Fig. 10 (b) shows the valve performance under high pressure input. Under inlet pressure of $55 \mathrm{psi}, 187 \mathrm{~mW}$ is sufficient to control a nitrogen flow of 2.5 liter/min. It can be seen that the valve shows serious hysteresis. It takes a lot of power to heat up the liquid to the working temperature and deflect the membrane. Once up to the temperature, it takes less power to keep the membrane deflected. The good thermal insulation of the valve package makes the problem worse by keeping the heat from dissipating away. The valve hysteresis can be decreased by attaching a metal heat sink to the valve package with the tradeoff that power consumption is increased.

\section{CONCLUSION}

A normally open low power thermopneumatic MEMS valve utilizing a composite silicone rubber/Parylene membrane has been designed, fabricated and tested. A novel suspended heater has been developed to reduce heat loss. By using a "soft" membrane with a large gap, and thermopneumatic actuation, high flow rates are achievable while still keeping power consumption low. A new valve seat has been developed to reduce the leak rate of the valve when the valve is closed. The steady state and transient response of the thermopneumatic action have been studied. The valve shows very low power consumption. $61 \mathrm{~mW}$ of power is sufficient to control a nitrogen flow of $1.1 \mathrm{lpm}$ with an inlet pressure of $24 \mathrm{psi}$.

\section{ACKNOWLEDGMENTS}

This work is supported by the DARPA MICROFLUMES program under Naval Ocean Systems Center Contract N66001-96C-83632. The authors would like to thank Ms. Ellis Meng for help with testing and Mr. Trevor Roper for help with processing.

\section{REFERENCES}

1. X. Yang, C. Grosjean, Y.-C. Tai, and C.-M. Ho, "A MEMS Thermopneumatic Silicone Membrane Valve", Proceedings of IEEE the $10^{\text {th }}$ Annual International Workshop on Mciro Electro Mechanical Systems, Jan 26-30, 1997, Nagoya, Japan, pp.114-118.

2. M. Zdeblick, R. Anderson, J. Janskowski, B. Kline-Schoder, L. Christel, R. Miles and W. Weber, "Thermopneumatically Actuated Microvalves and Integrated Electro-fluidic Circuits", Technical Digest of the 1994 Solid State Sensor and Actuator Workshop, Hilton Head Island, SC, June 13-16, 1994, pp. 251-255.

3. L. Bousse, E. Dijkstra and O. Guenat, "High Density Array of Valves and Interconnects for Liquid Switching", Technical Digest of the 1996 Solid State Sensor and Actuator Workshop, Hilton Head Island, SC, June 3-6, 1996, pp. 272-275.

4. P. L. Bergstrom, J. Ji, Y.-N. Liu, M. Kaviany, and K. D. Wise, "Thermally Driven Phase-Change Microactuation", Journal of Microelectromechanical Systems, Vol. 4, No.1, 1995, pp. 10-17.

5. C. Vieider, O. Ohman and H. Elderstig, "A Pneumatically Actuated Microvalve with a Silicone Rubber Membrane for Integration with Fluid Handling Systems", Technical Digest of the

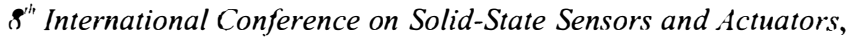
Vol. 2, June, 1995, pp. 284-286.

6. O. Tabata, K. Kawahata, S. Sugiyama and I. Igarashi, "Mechanical Property Measurements of Thin Films Using Load Deflection of Composite Rectangular Membranes", Sensors and Actuators, 20 (1989) pp. 135-141. 